\section{ALGUNS FATORES ASSOCIADOS COM O DESEMPENHO DE SUÍNOS DUROC AOS 21 DIAS DE IDADE}

\section{ANTONIO PEDRO SCHLINDWEIN}

Professor Livre Docente

Faculdade de Medicina Veterinária e Zootecnia da USP

FRANCISCO A.M. DUARTE

Professor Adjunto

Faculdade de Medicina de Ribeirão Preto da USP

LUIZ A.F. BEZERRA

Analista de Sistema

Centro de Computação do Departamento de

Genética e Matemática Aplicada à Biologia

Faculdade de Medicina de Ribeirão Preto da USP

SCHLINDWEIN, A.P.; DUARTE, F.A.M.; BEZERRA, L.A.F. Alguns fatores associados com o desempenho de suínos Duroc aos 21 dias de idade. Rev. Fac. Med. vet. Zootec. Univ. S. Paulo, 19(2): 189-94, 1982.

RESUMO: A partir de 529 leitegadas de suínos da raça Duroc, criados na Estação Experimental de Zootecnia, jertãozinho, SP, no periodo de 1957 a 1970 , foram estudados os efeltos de ano e apoca do ano de nascimento e ordem de parição sobre tamanho e peso da leitegada aos 21 dias de idade. O número médio de leitões por leitegada foi de 5,59 e o peso médio da leitegada foi de 25,63 $\mathrm{kg}$. A idade da porca ao parto, revelou-se importante causa de variação sobre as características estudadas. As maíores medias, em geral, ocorreram à idade de 34-39 meses ou ao quarto-quinto parto, das porcas.

UNITERMOS: Peso, leitegada "; Suínos, desempenho"; Suĺnos, leitegada *; Fatores nåo gen éticos

\section{INTRODUÇÃO}

As informações sobre a leitegada à idade de 21 dias vem se constituindo em subsídios cada vez mais importantes sobre o desempenho produtivo à medida que alterna tivas de idade de desmama estão sendo adotadas pelos criadores. A pesagem aos 21 dias de idade como informativo da habilidade materna assume, assim, relevância ainda maior por permitir comparações de desempenhos de leitegadas desmamadas precocemente, o que normalmente ocorre após a terceira semana de vida.

A variação atribuivel aos fatores não genéticos fornece uma indicação para o controle e indica o tipo especifico de programa de criação que faculte o maior progresso global.

$O$ objetivo do presente trabalho e diferenciar as influências de alguns fatores não genéticos que incidem na variabilidade do tamanho e peso de leitegada aos 21 dias de idade, em suínos da raça Duroc, criados em Sertãozinho, São Paulo, e avaliar a aplicação dos resultados para a criação animal.

\section{LITERATURA}

Os métodos obtidos por O'FERRAL e cols 5 (1968) em diversas linhagens e cruzamentos nos Estados Unidos, indicam que houve influência de ano sobre a variação do peso da leitegada aos 21 dias de idade.

URBAN JUNIOR e cols 8 (1966), encontraram efeito estatisticamente significativo de estação do ano (primavera e outonol sobre o tamanho da leitegada aos 21 dias, estudando diversas raças criadas nas estações experimentais de Indiana, Oklahoma e Wiscousin. LEGAULT4 (1969), entretanto, em suínos Large White, no período de 1958 1964, concluiu ser pequena a importância do efeito de mês de nascimento sobre o número de leitões por leitegada a três semanas devida.

CARNEIRO1 (1958), em observações de diversas raças criadas em Minas Gerais, encontrou que as maiores leitegadas aos 21 dias de idade ocorreram em porcas de 36 a 42 meses de idade. $O$ autor comenta que, embora as diferenças entre idades no tamanho da leitegada fossem estatisticamente significativas, é pequena a importância desta causa de variação.

Estudando um rebanho Piau em Minas Gerais, CARNEIRO e cols ${ }^{2}$ (1966) acharam efeito significativo da idade da matriz sobre o tamanho da leitegada, havendo um aumento progressivo do número de leitões por leitegada a partir do primeiro ano de idade da matriz até aos 60 meses, quando decresceu. A participação desta fonte de variação foi de $11 \%$ na variabilidade do número de leitões.

Em animais Large White, na França, LEGAUT4 (1969) verificou que a significância estatística do efeito da ordem do parto sobre número de leitões por leitegada aos 21 dias, decorre da grande diferença existente entre 
- primeiro e o segundo parto, sendo que este acréscimo se mantém estável até a quarta parição.

\section{MATERIAL E MÉTODOS}

Os dados do presente trabalho, referentes ao perlodo de 1957 a 1970, foram obtidos das fichas zootécnicas do Posto de Suinocultura da Estação Experimental de Zootecnia, da Secretaria da Agricultura, localizada em Sertãozinho, Estado de São Paulo.

O Posto de Suinocultura encontra-se a uma altitude de $548 \mathrm{~m}$, a $21^{\circ} 8^{\prime}$ de latitude $S$ e 4705

de 548m, a 2108' de latitude S e 47059' de longitude W.Gr., apresentando clima tropical, tipo savana, com uma temperatura média anual de $21,10 \mathrm{C}$ e chuvas irregulares com uma precipitação média de $1112 \mathrm{~mm}$.

O solo é argilo-silicoso de origem basáltica, a chamada terra-roxa, considerado de boa fertilidade.

Foram estudadas 529 leitegadas e 2944 leitões, provenientes de 41 reprodutores e 226 matrizes da raça Duroc.

O manejo do rebanho foi o rotineiro em uma criação comercial, em regime de semi-confinado. Descrição mais detalhada a respeito encontra-se em SCHLINDWEIN e DUARTE 7 (1980).

As decisões estatisticas foram tomadas a nivel de $5 \%$ (influência significativa), a partir do teste $F$, sendo os efeitos significativos assinalados com asterisco nos respectivos quadros de análise de variância.

Inicialmente as análises se desenvolveram em torno da obtenção de médias, desvios padrão e coeficientes de variação das características abordadas, em relação aos fatores: ano e época do ano em que ocorreram os nascimentos, idade da matriz por ocasião do parto, em meses, e/ou ordem de leitegada.

Empregou-se indistintamente as expressões "número de leitões por leitegada" e "tamanho da leitegada" para designar a freqüência de leitões nascidos vivos em cada parto.

Para o estudo da influência da época de nascimento, os dados observados no mesmo ano foram agrupados em periodos de seis meses, de abril a setembro (outono-inverno) e de outubro a março (primavera-verão). Com a mesma finalidade, as idades da porca em que ocorreram os partos foram reunidas em classes de intervalos de seis meses, resultando oito grupos de idades. As idades superiores a 52 meses, devido à sua baixa freqüência, constituiram uma classe única.

As estimativas dos fatores de variação foram obtidas pelo método dos quadrados mínimos, segundo HARVEY 3 (1960), adotando-se o seguinte modelo matem ático:

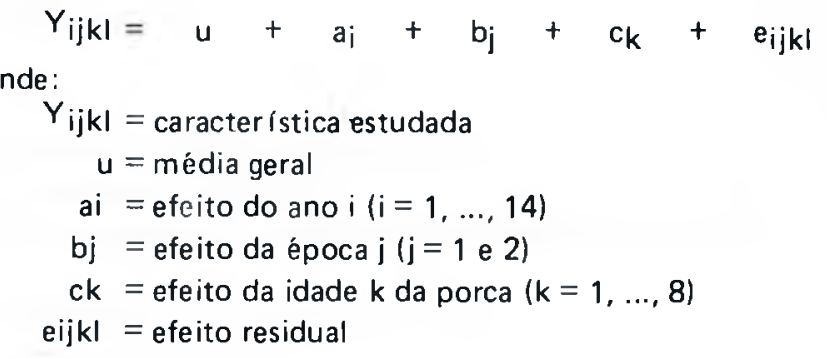

\section{RESULTADOS}

No perlodo considerado, 1957 a 1970, o primeiro quinqüênio (1957-1962), de um modo geral, caracteri. zou-se por apresentar a maioria dos valores inferiores à mêdia nas variáveis consideradas. A partir de 1962-64 houve uma tendência de as médias aumentarem gradualmente para as caracter Isticas estudadas, sendo que o descenso verificado no ano de 1968 se deve ao pequeno número de observações nesta classe.

As constantes de ajustamento para ano das características consideradas encontram-se no quadro 1 .

$O$ efeito de ano revelou-se estatisticamente não significativo, tanto para tamanho para peso da leitegada, conforme o apresentado na tabela 1 .

A participação do valor ano na variabilidade do tamanho e peso da leitegada foi nula (tabela 2).

$\mathrm{Na}$ distribuição das constantes de ajuste de tamanho de leitegada (quadro 1), verificou-se um progressivo aumento com os anos até 1961-64, para então, ocorrer o declínio.

Os objetivos de aproveitamento do primeiro cio manifestado pelas marrãs em idade de reprodução, e de obten. cão de dois por porca em cada ano, tornam bastante alta a relação entre ordem de leitegada $\mathrm{e}$ idade da porca ao parto, possibilitando grande analogia entre os dois critérios.

O tamanho e o peso da leitegada revelaram efeito estatisticamente significativo de idade da matriz ao parto (tabela 1), sendo esta causa de variação responsável por fração razoável da variabilidade total das características envolvidas (tabela 2).

A análise das constantes de ajustamento indicam que os maiores valores encontram-se nas classes $10 \cdot 15$ e 34 - 39 meses.

Generalizando para o conjunto das observações nota-se que as constantes de menor valor ocorrem nas classes mais extremas, (16 - 21 e acima de 39) de tal forma que os maiores valores negativos pertencem à penúltima classe (46 - 51 meses) e para peso da leitegada à segunda classe (16 - 21 meses). 
QUADRO 1 - Constantes de ajustamento de tamanho e peso de leitegada aos 21 dias. de idade para os efeitos de ano e época de nascimento, e idade da matriz do parto.

\begin{tabular}{|c|c|c|c|c|}
\hline \multirow[t]{2}{*}{ Efeitos } & & \multirow{2}{*}{$\begin{array}{l}\text { Número de } \\
\text { Observaç̃es }\end{array}$} & \multicolumn{2}{|c|}{ Constantes } \\
\hline & & & Tamanho & Peso (kg) \\
\hline \multirow[t]{8}{*}{ Média geral } & & 529 & 5,834 & 26,196 \\
\hline & 1957 & 2 & $-1,437$ & $-0,240$ \\
\hline & 1958 & 57 & $-0,721$ &,- 6731 \\
\hline & 1959 & 28 & 0,506 & $-1,668$ \\
\hline & 1960 & 31 & $-0,127$ & $-4,198$ \\
\hline & 1961 & 40 & 1,238 & 0,996 \\
\hline & 1962 & 62 & 1,072 & 2,495 \\
\hline & 1963 & 78 & 0,372 & 2,461 \\
\hline \multirow[t]{6}{*}{ Ano de nascimento } & 1964 & 65 & 0,713 & 1,850 \\
\hline & 1965 & 50 & 0,325 & 2,008 \\
\hline & $\begin{array}{l}1966 \\
1967\end{array}$ & $\begin{array}{l}31 \\
22\end{array}$ & $\begin{array}{l}-0,015 \\
-0,345\end{array}$ & $\begin{array}{l}4.923 \\
4,419\end{array}$ \\
\hline & 1968 & 2 & $-0,305$ & $-0,362$ \\
\hline & 1969 & 18 & $-0,581$ & 2,038 \\
\hline & 1970 & 43 & $-0,695$ & 1,009 \\
\hline \multirow[t]{4}{*}{ Época do ano } & 1 & 271 & 0,007 & $-0,070$ \\
\hline & 2 & 258 & $-0,007$ & 0,070 \\
\hline & $10-15$ & 141 & 0,593 & 1,568 \\
\hline & $16-21$ & 90 & $-0,401$ & $-2,903$ \\
\hline Idade da matriz & $22-27$ & 92 & 0,037 & 0,097 \\
\hline \multirow[t]{5}{*}{ ao parto (meses) } & $28-33$ & 68 & 0,324 & 0,948 \\
\hline & $34-39$ & 53 & 0,468 & 2,524 \\
\hline & $40-45$ & 42 & $-0,072$ & $-0,583$ \\
\hline & $46-51$ & 21 & $-0,725$ & $-2,538$ \\
\hline & 51 & 22 & $-0,224$ & 0,842 \\
\hline
\end{tabular}

TABELA 1 - Análises de variância de tamanho e peso $(\mathrm{kg})$ de leitegada aos 21 dias de idade

\begin{tabular}{l|rrcr}
\hline Fontes de variação & Graus de Liberdade & Leitegada & Peso \\
\hline Entre anos & 13 & 2,683 & 45,577 \\
Entre épocas & 1 & 0,019 & 2,099 \\
Entre idades & 7 & $10,117^{*}$ & $196,757^{*}$ \\
Residuo & 468 & 4,848 & 85,054 \\
\hline
\end{tabular}

* = Significativo a $\mathrm{P}<0,05$ 
TABELA 2 - Participação (\%) dos efeitos considerados na redução da soma de quadrados total para as características estudadas

\begin{tabular}{l|cr}
\hline Efeitos & Tamanho de leitegada & Peso de leitegada \\
\hline Ano & 0,00 & 0,00 \\
Epoca & 0,00 & 0,00 \\
Idade & 2,60 & 2,40 \\
Erro & 96,12 & 95,71 \\
\hline
\end{tabular}

As correlações apresentadas na tabela 3 indicam, de um modo geral, que tamanho e peso da leitegada não são estatisticamente correlacionados com as produções dos partos subseqüentes.

TABELA 3 - Correlações de tamanho e peso de leitegada, entre ordens de parição

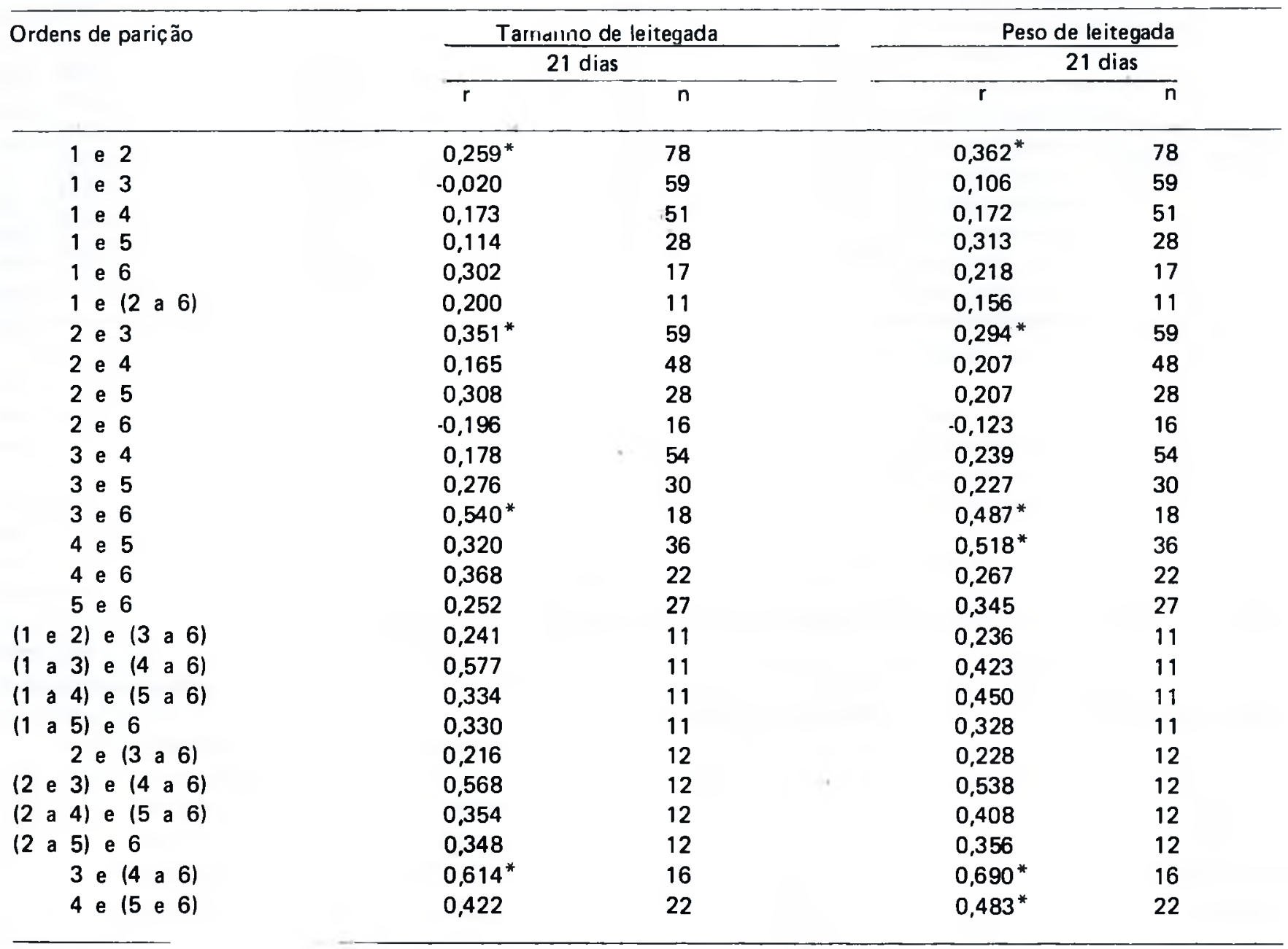

$=$ sıgnıficativo a $P<0,05$ 


\section{DISCUSSÃO E CONCLUSÃO}

A influência não significativa de ano, verificada no presente trabalho, sobre o peso e tamanho de leitegada aos 21 dias de idade não concordam com o verificado em O'FERRAL e cols ${ }^{5}$ (1968).

As variações encontradas entre anos, resultam provavelmente de alterações das condições sanitárias, climáticas, de manejo, de alimentação e até mesmo de administração, de ocorrência freqüente na condução de um rebanho. Desta forma, o efeito ano de nascimento, representa não uma causa singular de variação, mas sim um conjunto de fatores complexos, dificilmente isoláveis em uma análise estatística.

Parte das diferenças entre anos, podem ser atribuídas à superioridade genética, resultantes da concentração em alguns anos de reprodutores e matrizes de potencial hereditário mais adequado para os propósitos que envolvem as características abordadas neste trabalho.

As características consideradas no presente estudo, não revelaram influência significativa da época do ano em que nasceram. Os mesmos resultados, são encontrados em LEGAULT 4, (1969), enquanto que conclusões contrárias são referidas por URBAN JÚNIOR e cols 8 (1966).

As variações mensais nas médias dás varacteristicas estudadas, indicam afastamentos consideráveis em diferentes meses dentro das épocas nas quais o ano foi dividido para o presente trabalho. Assim, deve-se notar que, nos meses de maio e setembro, o número médio de leitões e peso da leitegada aos 21 dias de idade foram 8 a $12 \%$ inferiores à média. Afastamento semelhante, porém em sentido contrário, observa-se em fevereiro, julho e dezembro, quando tamanho e peso da leitegada foram $6 \%$ acima da média. Isto faz supor que o próprio critério de divisão do ano em apenas duas épocas teria eliminado as possíveis variações mensais. Se as análises tivessem sido desenvol. vidas entre meses, possivelmente outros resultados seriam obtidos.
Um fator que, possivelmente, contribui para o efeito de idade é o descarte de algumas matrizes menos produtivas. Se tal eliminação for efetiva, é de se esperar uma menor variabilidade nos grupos de idade mais alta.

O sistema de manter as matrizes por um período curto é anti-econômico, pois a reversão financeira adviria pela maior diluição dos gastos feitos em relação ao número de leitões produzidos no período de vida, embora o des carte precoce por seleção, diminua o intervalo de gerações. É preciso, ainda, lembrar que as primeiras leitegadas não constituem o melhor critério para avaliar eficazmente o desempenho reprodutivo da matriz. Ainda sob o aspecto econômico é muito importante conhecer a rapidez com que é atingido o máximo de leitões por leitegada, a persistência da prolificidade a niveis altos, e o seu declínio nas leitegadas seguintes. E este desempenho é especifico, não de rebanho, mas, provavelmente, de cada matriz.

SCHLINDWEIN, A.P.; DUARTE, F.A.M.; BEZERRA, L.A.F Some factors associated with the performance of Duroc swine at 21 days of age. Rev. Fac. Med. vet. Zootec. Univ. S. Paulo. 19(2): 189-94, 1982.

SUMMARY: The effects of year and season of birth and farrowing order on litter size and litter weight at 21 days of age were studied for 529 litters of Duroc swine raised at Estação Experimental de Zootecnia, Sertãozinho, SP, from 1957 to 1970 . The mean number of piglets per litter was 5.59 and mean litter weight was $25.63 \mathrm{~kg}$. Sow age at farrowing was found to be an important cause of variations in the traits studied. The highest means occurred in general at 34-39 months of sow's age or at the fourth-fifth farrowing.

UNITERMS: Litter size"; Litter weight *; Swine performance"; Non-gene tic factors

\section{REFERÊNCIAS BIBLIOGRÁFICAS}

1 - CARNEIRO, G.G. Número de leitões na leitegada e seu peso total como medida de avaliação da produtividade de porcas. Arq. Esc. Sup. Vet. Univ. Rural Est. M. Gerais, 11:169-98, 1958.

2 - CARNEIRO, G.G.; MEMORIA, J.M.P.; MONTEIRO, J.R. Estudo sobre a produtividade da porca Piau em Minas Gerais. Arq. Esc. Sup. Vet. Univ. Fed. M. Gerais, 18:11-6, 1966.
3 - HARVEY, W.R. Least squares analysis of data with unequal subclass numbers. Washington, United States Department of Agriculture, 1960. $157 \mathrm{p}$. (ARS, 20-8).

4 - LEGAULT, C. Etude statistique et génétique des performances d'élevages des truies de la race Large White. I. Effects du troupeau, de la période semestrelle, du numéro de portée et du mois de 
194 SCHLINDWEIN, A.P.; DUARTE, F.A.M.; BEZERRA, L.A.F.

naissance. Ann. Génét. Sél. anim., 1:281-98, 1969.

5 - O'FERRAL, G.L.M.; HETZER, H.O.; GAINES, J.A. Heterosis in preweaning traits of swine. J. anim. Sci., 27:17-21, 1968.

6 - SCHLINDWEIN, A.P. Fontes de variação de número e peso de leitões Duroc ao nascimento. Belo Horizonte, 1975. 81 p. (Tese de mestrado - Escola de Veterinária da UFMG).
7 - SCHLINDWEIN, A.P. \& DUARTE, F.A.M. Genetic study of pre-wearning performance in Duroc swine. Rev. bras. Genét., 3:407-20, 1980.

8 - URBAN JÚNIOR, W.E.; SHELBY, C.E.; CHAPMAN, A.B.; WHATLEY JÚNIOR, J.A.; GARWOOD, V.A. Genetic and environmental aspects of litter size in swine. J. anim. Sci., 25:1148-53, 1966.

Recebido para publicação em: 21-05-81. Aprovado para publicação em: 18-03-83. 